balance of grassland species but it seems that white clover (Trifolium repens) and meadow grass (Poa pratensis) may suffer more than red fescue (Festuca rubra), rye grass (Lolium perene) and crested dogstail grass (Cynosurus cristatus) ${ }^{7}$. Selection of specifically adapted genotypes within populations is difficult to demonstrate in the field, but experimental studies suggest that this will be an active process ${ }^{8}$.

The second consequence - the invasion of typically coastal species of plant - is more obvious to the observer and hence has been studied in more detail. In 1976, Mathews and Davison ${ }^{9}$ surveyed the Newcastle-upon-Tyne area and found several such species (such as Aster tripolium, Puccinellia distans, Plantago maritima and Sueda maritima) on roadside verges as much as $13 \mathrm{~km}$ from the sea. The salt marsh grass (Puccinellia distans) has now been recorded on verges extensively throughout northeastern England, in the Midlands, East Anglia and Kent ${ }^{10}$. Other species have not kept up with the rapid spread of Puccinellia, though the sea plantain (Plantago maritima) and the sea spurrey (Spergularia marina) are still advancing gradually. The sea aster (Aster tripolium), however, appears to have failed in its bid for a place in the new saline grasslands; seed set has been poor and populations are contracting rather than expanding. Seed dispersal techniques could be the key to success in this invasion. Puccinellia, Plantago and Spergularia are low-growing plants and their seeds could easily be carried in the mud adhering to vehicle tyres, while Aster seeds are produced well above the ground and rely on wind dispersal.

A survey of roadside vegetation in Norfolk has also recently been conducted by Bull ${ }^{11}$. Permanent recording plots were set up five years ago and the species present recorded annually since then. Both extinctions and immigrations have been observed during this time and Bull regards many of the new immigrants (for example, Polygonum aviculare, Artemisia vulgaris and Rumex obtusifolius) as salt tolerant. The difficulty in interpreting this kind of data is the number of variables involved (frequency and time of mowing in particular); controlled experimental studies are evidently needed.

The invasion of our roadside verges by halophytes is thus proceeding in much the way that the 'railway flora' developed

1. Moors. P.U. Nature 263, 189 (1976)

2. Westing, A.H. Phytopathology 59, 1174 (1969)

. Darison, A W J appl Ecol 8.555(1971).

Malloch, A

J.C. J. Ecol. 60, $103(1972$

Ecol 55, $1(1967)$

6. Allen, S.E., Carliste, A., Whice, E.J. \& Esans, C.C. J. Ecol. 56, 479 (1968)

7. Bannister, P. Introduction to Physiological Plant Ecology, 198 (Blackwell Scicntific. Oxford, 1976)

8. Rush, D.W. \& Epstcin, E. Pl. Physiol, 57, 162 (1976).

9. Mathew's, P. \& Davison, A.W. Hatsonia 11, $146(1976)$

10. Scot1, N.E. \& Davison, A. W. Watsonia 14, 41 (1982).

1. Bull, A. Trans. Norfolk Norwich Nat. Soc. 26, 23 (1982).

11. Bull, A. Trans. Norfolk Norwich Nat. Soc. 26, 23 (1982). Perring, F.) 73 (Classey, Hampton, 1970).

13. Amenity Grasslands, the Need for Research (NERC riport. 1977). during Victorian times ${ }^{12}$. One difference is that the nature of the current change will be less conspicuous. Extinctions may be more abundant than immigrations, but these are less easily noticed by casual observers, and genetic modifications within our roadside plants may also be overlooked. We may be sure, however, that there are subtle changes afoot in our $1,500 \mathrm{~km}^{2}$ of roadside verges $^{13}$.

\title{
Seawater under extreme pressure
}

\section{from Michael Whitfield}

UNTIL recently, the experimental difficulties involved in performing precise measurements at high pressures have ensured that relatively little information was available about the properties of seawater and the reactions of its constituents in ocean conditions. The available information has been scattered throughout the literature, uncorrelated and accessible only to the cogniscenti. Two recent publications $s^{1,2}$ indicate that this picture is changing rapidly.

Most experiments are carried out at atmospheric temperature and pressure, but it is a harsh reality that mean ocean conditions lie closer to $4^{\circ} \mathrm{C}$ and $200 \mathrm{~atm}$, and more extreme conditions are not uncommon. The pressure generated by the overburden of water has a significant influence on the density of seawater and hence on the stability of the water column and the direction and rate of water movement. Furthermore, minerals such as calcium carbonate and silica, generated in surface waters by biological processes, become progressively more soluble as they settle through the ocean, encountering waters at increasing pressures. Consequently the recycling of these minerals and the many trace elements associated with them is strongly dependent on the pressure sensitivity of the dissolution reactions. The solubility of calcium carbonate in the deep oceans is of particular concern since the dissolution of this mineral is likely to provide the final sink for the excess carbon dioxide currently being injected into the atmosphere by the combustion of fossil fuels. Another reason for growing interest in these measurements is the discovery of rich and diverse communities of organisms surrounding warm hydrothermal oases along the midoceanic ridges which are subjected to pressures of several hundred atmospheres.

To appreciate the significance of the recent developments one must look first at the problem of defining the equation of state for seawater, which enables the density of seawater to be calculated at a particular temperature, pressure and salinity. These parameters can be accurately measured and the calculated density fields

Michael Whitfield is at the Marine Biological Association of the United Kingdom, Plymouth $P L 12 P B$. then used to elucidate oceanic circulation patterns.

To establish the new equation of state for seawater, techniques were developed for the precise measurement of solution density over a wide range of temperature and pressure. Density measurements at atmospheric pressure for solutions of individual electrolytes found in seawater can be used to estimate the contributions made by the component ions to the solution volume (the ionic molal volumes). Similar measurements made at high pressure provide estimates of the ionic molal compressibility. The influence of pressure on a chemical reaction can be estimated from the accompanying volume change - a reaction which produces a decrease in volume being favoured by the application of pressure.

Millero $^{2}$ has taken advantage of recent density measurements at atmospheric pressure and at high pressure to compile data on ionic molal volumes and compressibilities over the temperature and pressure range of interest to oceanographers $\left(0-50^{\circ} \mathrm{C}, 1-1,000 \mathrm{~atm}\right)$. Using this information he has calculated the effect of pressure on the solubility of a range of mineral phases (including silica, strontium carbonate and calcium carbonate) and shown that the calculated values are in good agreement with available experimental data. Furthermore, by taking into account the molal compressibilities he was able to show that, for the minerals he considered, there was no need to invoke the presence of structurally altered zones at the surface of the solid phase to explain the observed pressure dependence. However, molal volume measurements over a wider temperature and concentration range will be needed in order to estimate the effects of pressure on reactions in the geothermal brines produced along saline spreading centres on the ocean floor. It is now becoming apparent that the reactions occurring at these sites may be responsible for fixing the concentration of many seawater components, and that the more spectacular deep-ocean vents may be surrounded by rich mineral deposits whose formation and stability require further investigation.

1. UNESC Backeround Papers and Supporting Data on the International Equation of State for Sea Water 1980 (Paris, 1981).

2. Millero, F.J. Geochim. cosmechim. Acla 46. 11 (1982) 